\title{
Políticas públicas, valorização da terra e metropolização: RMBH e o vetor industrial de expansão
}

\author{
Public policies, increase in land value and metropolization: \\ the Metropolitan Region of Belo Horizonte \\ and the expansion of the industrial vector
}

Sofia Santos Lages [I]

\begin{abstract}
Resumo
As especificidades da terra com relação aos demais bens configuram processos singulares de sua valorização e comercialização, em que o envolvimento dos agentes da produção do espaço é elemento estruturante na formação dos preços. 0 poder público, um desses agentes, apresenta papel notável, visto que possui a capacidade de controlar os possíveis usos da terra e, consequentemente, induzir atividades e empreendimentos que gerem atração do capital. Discute-se, neste artigo, a relação entre a atuação do poder público, a valorização da terra e a expansão de Belo Horizonte, desde seu plano inaugural até a metropolização, especialmente no "vetor oeste", associado às atividades industriais desde os primórdios de sua expansão.
\end{abstract}

Palavras-chave: metropolização; políticas públicas; valorização da terra; mercado da terra; Região Metropolitana de Belo Horizonte.

\begin{abstract}
The specificities of land in relation to other goods constitute unique processes of land value increase and land commercialization, in which the involvement of space production agents is a structuring element in the formation of prices. The State, one of these agents, plays a remarkable role, as it has the power to control the possible uses of land and, consequently, to induce activities and enterprises that generate capital attraction. This article discusses the relationship between the State's action, the increase in land value and Belo Horizonte's expansion, from its inaugural plan to metropolization, especially in the "west vector", associated with industrial activities since the beginning of its expansion.
\end{abstract}

Keywords: metropolization; public policies; increase in land value; land market; Metropolitan Region of Belo Horizonte. 


\section{Introdução ${ }^{1}$}

A conformação do espaço urbano é fruto da relação entre diversos fatores que se influenciam mutuamente. Nesse processo de múltiplas interferências, a terra é condição fundamental para que todas as atividades sejam realizadas, o que a configura como categoria específica no contexto da urbanização regida pelo modo de produção capitalista.

Argumenta-se, neste trabalho, que os chamados "agentes da produção do espaço"
(Corrêa, 1989) ou "agentes do mercado" (Plambel, 1987) têm importante papel no processo de metropolização, uma vez que a espacialização do território metropolitano é resultante, dentre outros aspectos, de suas disputas e interesses. 0 poder público como um desses agentes tem especial relevância na expansão e estruturação urbana, visto que, por ser o responsável pela determinação e controle do uso e ocupação do solo, tem a capacidade de induzir os processos de reprodução do capital por meio de regulamentações e políticas públicas.

Figura 1 - Mapa RMBH e colar metropolitano com destaque para vetor oeste de expansão definido neste trabalho

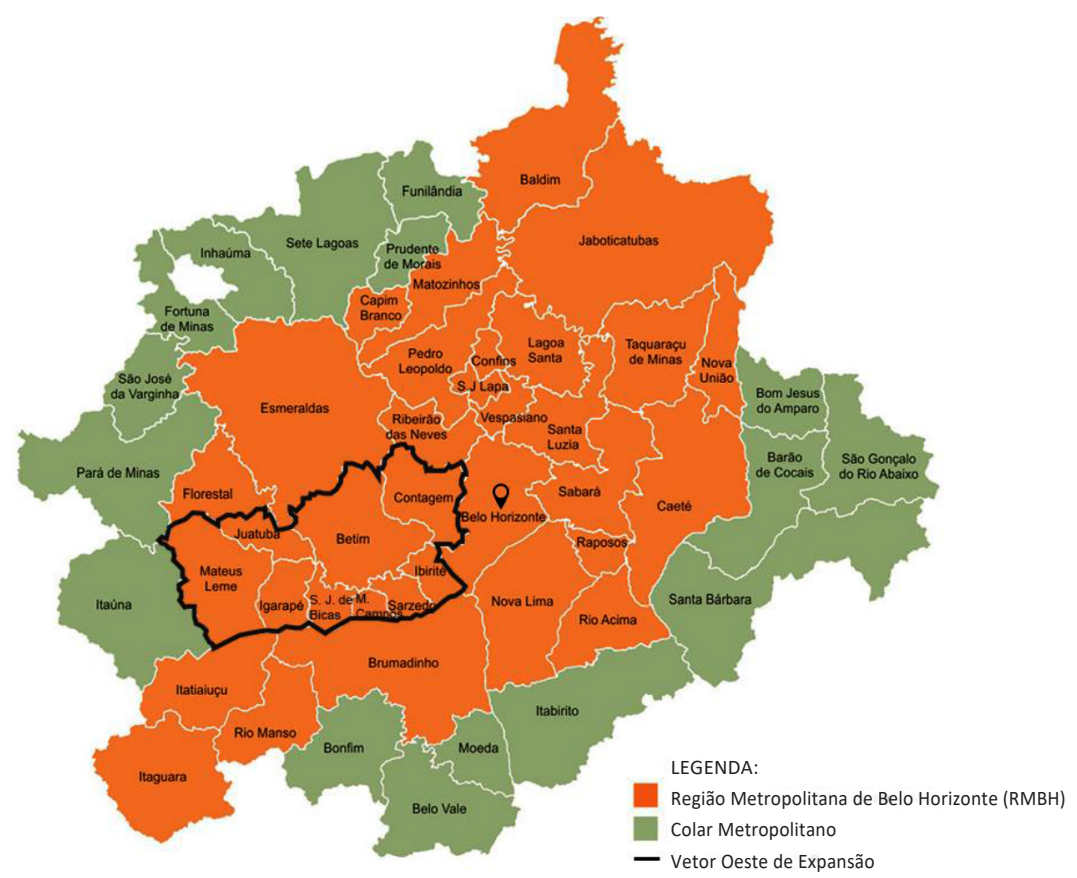

Fonte: Agência de Desenvolvimento da Região Metropolitana de Belo Horizonte, modificado pela autora, em 2019. 
Este artigo visa a discutir a relação entre a atuação do poder público, o processo de metropolização de Belo Horizonte e a valorização da terra nesse contexto. Serão abordados, especialmente, os reflexos das políticas públicas no chamado "vetor oeste de expansão" da Região Metropolitana de Belo Horizonte (RMBH), ${ }^{2}$ conformado pelos municípios de Contagem, Betim, Ibirité, Sarzedo, Mário Campos, São Joaquim de Bicas, Igarapé, Juatuba e Mateus Leme (Figura 1). Tal agrupamento tem origem nas macrounidades propostas pelo Plambel $^{3}$ (1986) e trabalhadas em Mendonça (2002), especialmente aquela chamada de "Eixo Industrial"; e foi ampliado com base em um dos pressupostos deste artigo de que o processo de expansão metropolitana é continuamente acentuado a oeste da RMBH a partir, dentre outras causas, da chamada reestruturação produtiva, processo iniciado na segunda metade do século XX. O agrupamento proposto fundamenta-se, ainda, no trabalho de Diniz e Andrade (2015) sobre a integração metropolitana dos municípios da RMBH. Segundo os autores, em 2010 o vetor oeste de expansão aqui determinado contava com municípios de integração média a muito alta. ${ }^{4}$ Tal conjuntura permite inferir que, até mesmo na extremidade do eixo proposto como recorte, as áreas urbanas não podem mais ser consideradas como desarticuladas e residuais, tal como no contexto de investigação de Plambel (1986), uma vez que já estão diretamente interligadas ao município-polo tanto fisicamente, pelos eixos viários, quanto social, logística e produtivamente.

A abordagem proposta neste artigo se estrutura, assim, nos seguintes eixos de discussão: inicialmente na caracterização do processo de valorização do espaço e formação dos preços da terra - cujos principais referenciais teóricos utilizados são Moraes e Costa (1984) e, especialmente, Jaramillo (2009) - com o intuito de aplicar a Teoria da Renda da Terra Urbana como base teórica para a análise do mercado da terra metropolitana; em seguida na elucidação do papel dos agentes de mercado nesse processo, em especial o poder público, segundo os trabalhos de Plambel (1987), Correa (1989) e Jaramillo (2009), em uma tentativa de aproximação da estrutura atual de interação entre esses agentes e a produção do espaço; e, por fim, na descrição da expansão urbana e metropolização de Belo Horizonte, desde seu plano inaugural até a atualidade, com destaque para os reflexos das decisões e políticas públicas nesse processo, particularmente no vetor oeste de expansão, sendo Plambel (1986), UFMG (2011), e Tonucci Filho (2012) os trabalhos estruturantes para essa argumentação.

\section{Valorização do espaço e mercado da terra: suporte ao processo de metropolização}

No estudo dos processos de valorização da terra, duas vertentes importantes podem ser identificadas: a teoria utilitarista, associada fundamentalmente à ideia de localização; e a teoria do valor-trabalho, desenvolvida por Karl Marx (1818-1883) na elaboração da Teoria da Renda da Terra, relevante na compreensão deste trabalho (Almeida e Monte-Mór, 2017).

Apoiadas na ideia de sistemas de competição perfeita e produtos homogêneos, as teorias de localização clássicas e neoclássicas tinham como interesse principal a 
maximização de ganhos de um determinado uso em localidades estabelecidas. Nesses trabalhos, a localização era associada exclusivamente à ideia de distância. 0 modelo de Heinrich Von Thünen (1783-1850), primeiro estudo sobre "aspectos geográficos da economia clássica" (Parnreiter, 2018), discute a renda da terra agrícola e sua organização no espaço, utilizando como variável a distância como custo de transporte. Nele se basearam outros modelos, tais como o de William Alonso (1933-1999), sobre a valorização da terra urbana em função de preferências locacionais; e o de Richard Muth (1927-2018) e Edwin Mills (1928-), que utilizam a densidade como variável principal para a compreensão da estruturação urbana (Plambel, 1987). Tal qual a proposta de Von Thünen, outros modelos também apresentam relevância para a construção das teorias de localização, dentre os quais o de Alfred Weber (1868-1958), interessado em determinar a localização ótima para determinados seguimentos industriais, baseado principalmente nos custos de transporte; de August Lösch (1906-1945), que define as áreas ótimas de mercado; e de Walter Christaller (1893-1969), de localização orientada pelo mercado, que complementarmente conformam a Teoria do Lugar Central. ${ }^{5}$

Apesar da relevância desses modelos nos primórdios da discussão sobre as questões urbana e regional, especialmente no contexto em que foram desenvolvidas, as especificidades espaciais não são aí contempladas. 0 espaço é tratado, nessas teorias, de modo uniforme no que diz respeito tanto aos aspectos físicos quanto aos sociais, ou seja, como uma abstração da realidade e das relações que o conformam. Em síntese, como um espaço fictício, abstrato e livre de conflitos (ibid.).
O espaço real, não abstrato, e mais especificamente a terra, é singular como objeto de valorização e não se confunde com os demais produtos materiais (Moraes e Costa, 1984). Primeiramente se diferencia por não ser produto de trabalho ao mesmo tempo que se configura como condição para a realização de todas as atividades. Além de imóvel e fisicamente absoluta - não pode ser ocupada por dois corpos simultaneamente -, a terra é um bem não fungível, ou seja, não se extingue em decorrência do uso, apenas se altera; é uma matéria finita, logo apresenta oferta inelástica de mercado; é heterogênea na qualidade de condição de produção e reprodução; e reflete a acumulação de trabalho nela realizado, como uma sobreposição do resultado de processos históricos naturais e sociais.

Marx, em uma tentativa de considerar as especificidades da terra agrícola e de seu mercado, resgata dos estudos de David Ricardo (1772-1823) e incorpora, em sua Teoria da Renda da Terra, a importância da distância relativa e da fertilidade do solo como princípios de análise da valorização do espaço. Pensada para explicar a conjuntura das terras agrícolas, duas dimensões da teoria marxista são levantadas como fundamentais para os estudos posteriores do solo urbano: a primeira delas diz respeito à relação entre valor e trabalho. Crítico da teoria clássica de valor-trabalho herança de Adam Smith (1723-1790) e David Ricardo -, Marx defende não existir valor sem trabalho e, nesse sentido, o processo de valorização da terra apresentaria uma estrutura específica em relação aos demais mercados, uma vez que não é produzida a partir do trabalho humano. Logo, falar de valor da terra significaria falar sobre outro tipo de ganho: a renda. A segunda questão fundamental de seus estudos 
para a discussão aqui iniciada é a constatação de que todas as terras auferem algum tipo de renda, mesmo que apenas as rendas absolutas, a saber, rendas mínimas referentes aos piores solos e localizações, e que determinam o gradiente de valorização do espaço (ibid.).

Assim, a renda da terra pode ser definida como o montante, independente da moeda de troca, recebido pelo proprietário como compensação do uso daquele espaço. A existência da renda é fruto da propriedade privada dos meios de produção, e seus diferentes tipos são gerados em decorrência das especificidades de cada terra (idib.; Jaramillo, 2009; Singer, 1982).

Samuel Jaramillo (1950-), economista e teórico urbano colombiano, propõe-se a atualizar os conceitos de renda presentes na teoria de Marx segundo as particularidades da terra urbana. Enquanto Marx divide os diferentes tipos de renda das terras agrícolas em renda diferencial do tipo I, do tipo II, renda absoluta e de monopólio, Jaramillo classifica as rendas das terras urbanas em primárias - diferencial do tipo I, tipo II e absoluta - e secundárias diferencial de comércio, de monopólio de segregação, diferencial de habitação, diferencial e de monopólio industrial (Jaramillo, 2009).

\section{As rendas urbanas primárias e secundárias}

Jaramillo (ibid.) denomina "rendas urbanas primárias" aquelas implicadas no processo produtivo da construção, daí sua semelhança com as rendas definidas por Marx, também associadas à noção de produção, no caso, a agricultura. Essas rendas têm relação com as possibilidades e especificidades dos terrenos, especialmente com o processo de construção em si - custos de infraestrutura e de verticalização, por exemplo. Já as "rendas urbanas secundárias" são aquelas originadas do consumo do espaço construído, associadas aos seus usos possíveis e desejáveis em um determinado contexto. Segundo o autor, as relações entre as rendas urbanas dão-se de modo distinto no espaço: as rendas primárias apresentam complementaridade entre si enquanto as secundárias configuram um processo de competitividade pelo espaço.

Para o autor, a renda primária diferencial do tipo I caracteriza-se como produto da diferença de constructibilidad dos terrenos, ou seja, suas especificidades construtivas, bem como os gastos e ganhos que podem gerar. Dentre essas características, Jaramillo destaca as condições geomorfológicas e a localização especialmente em relação à disponibilidade de infraestrutura. Já a renda primária diferencial do tipo // está relacionada à quantidade de capital investido na terra, a fim de possibilitar a verticalização. A renda absoluta urbana, nível mínimo de renda para todos os terrenos, relaciona-se, assim como a renda absoluta tratada por Marx, à escassez da terra decorrente da propriedade privada, além de se configurar como base sobre a qual se estruturam os demais preços da terra (ibid.).

Quanto às rendas secundárias, Jaramillo chama de renda diferencial de comércio aquela auferida pelos proprietários das terras cuja inserção no contexto urbano consegue gerar uma rotação mais rápida do capital comercial, possibilitando lucros extraordinários não reprodutíveis pelo capital individual. A renda de monopólio de segregação tem relação direta com a disponibilidade de determinados segmentos sociais em pagar valores mais altos 
para ocupar lugares que são conhecidos como exclusivos e diferenciais no que se refere tanto à localização - sua proximidade em relação às chamadas amenidades urbanas -, quanto ao tipo de ocupação em si, como é o caso dos condomínios fechados e sua suposta oferta de segurança e singularidades. 0 processo de segregação socioespacial da metrópole é diretamente influenciado pela conformação dessa renda, uma vez que determina valores da terra inacessíveis à maior parcela da população, logo, espacializa as localizações possíveis de serem ocupadas pelo segmento social. Já a renda diferencial de habitação, cujas características fundamentais a assemelham à renda de segregação, tem como princípio a capacidade e a disposição das famílias em arcar com os custos de localizações favoráveis à sua moradia. Importa ressaltar que, nesse caso, segundo o autor, a dimensão da proximidade dos valores de uso complementares ao modo de vida singular de cada família é o que determina as demandas pela localidade especificamente (ibid.).

No que se refere à renda diferencial e de monopólio industrial, Jaramillo (ibid.) esclarece que, com o desenvolvimento tecnológico e dos transportes, a atividade industrial, que demanda grandes áreas para sua implantação, não disputa as terras mais bem localizadas no contexto urbano e, portanto, com rendas mais altas. Desse modo, o autor comenta que as rendas diferencial e de monopólio industrial apresentam caráter secundário, uma vez que, mesmo relacionadas à atividade produtiva, têm caráter de consumo do espaço e não de produção. Apesar disso, o fato de ser uma atividade cujo impacto é conflituoso com outros usos do solo, a localização industrial é geralmente controlada pelo poder público.
Esse controle é relevante para a abordagem desenvolvida neste trabalho, tendo em vista que existe uma influência na renda das terras próximas às áreas determinadas como industriais, reflexo notável tanto nas rendas comerciais quanto nas de habitação, de acordo com cada contexto (ibid.).

Assim, argumenta-se, neste artigo, que a atualização proposta por Jaramillo (ibid.) permite uma visão mais clara da complexidade existente na formação da renda da terra urbana do que é possível a partir das teorias de localização e mesmo da Teoria da Renda da Terra Agrícola. Tal abordagem propicia, ainda, compreender o papel estruturante dos preços do solo e sua relação com a valorização do espaço no processo de metropolização, tema que será discutido com mais detalhe nas seções sobre a RMBH.

\section{Os agentes de mercado e a produção do espaço metropolitano}

Assim como a compreensão da formação da renda da terra urbana, outro aspecto fundamental para se interpretar a valorização do espaço e a estruturação metropolitana é a interação entre os distintos agentes que conformam tal processo (ibid.; Plambel, 1987; Corrêa, 1989). Cabe salientar que a existência e o papel desses agentes são específicos de cada contexto condicionados a processos sociais, históricos, políticos e econômicos próprios, apesar de regidos pela rede capitalista global e sua divisão do trabalho. Desse modo, tanto quanto as singularidades da terra, 
as particularidades dos agentes envolvidos no processo de valorização da terra tornam fundamental a delimitação de um recorte espacial para sua análise.

Corrêa (1989, p. 43) comenta que "os agentes sociais da produção do espaço estão inseridos na temporalidade e na espacialidade de cada formação socioespacial capitalista", e os classifica em: proprietários dos meios de produção, proprietários fundiários, promotores imobiliários, o Estado e os "grupos sociais excluídos”. Para Plambel (1987, p. 75) “a análise da atuação dos vários tipos de agentes do mercado de terrenos urbanos é relevante porque é a lógica de sua atuação, na busca de apropriação da renda da terra ou da apropriação de vantagens locacionais, que determina a estruturação urbana". Na abordagem de Plambel (ibid.) os agentes são separados entre o Estado e o setor privado, quais sejam: os usuários, os proprietários urbanos e das áreas urbanizáveis, os capitalistas empreendedores e os intermediários.

Com o intuito de atualizar tais definições de agentes para a conjuntura atual do mercado de terras e imobiliário, bem como aproximá-las da escala da metrópole brasileira, faz-se importante separar os agentes da produção formal e informal do espaço metropolitano. Abramo (2007, p. 29) utiliza das definições de Bagnasco (1999) para caracterizar os mercados formais e informais:

Se chamamos de economia formal o processo de produção e de trocas de bens e serviços regulados pelo mercado e promovidos e realizados por empresas industriais e comerciais com o objetivo do lucro e que atuam submetidas às regras do direito comercial, fiscal, do trabalho, etc., podemos chamar economia informal todo o processo de produção e de troca que não se submete a um desses aspectos.

Para tal atualização da caracterização dos agentes, neste artigo, os agentes formais são identificados como: o Estado, como poder público, e os órgãos de interferência metropolitana; o Serviço de Registro de Imóveis, sob a figura do oficial responsável pelos registros dos parcelamentos e empreendimentos, além das transações que legitimam a propriedade formal, caracterizado como serviço público; proprietários fundiários e imobiliários; empresas urbanizadoras; incorporadores e construtores; intermediários do mercado - arquitetos e urbanistas, publicitários, imobiliárias, corretores; instituições e agentes financeiros; e, por fim, os usuários. A definição dos agentes informais faz-se muito mais complexa, uma vez que o mapeamento do seu mercado é dificultado pelas condições e pelo funcionamento de cada contexto, bem como por relações específicas de confiança, como comenta Abramo (ibid.). Assim, por se tratar neste trabalho de uma reflexão ampla sobre o contexto metropolitano, com foco no papel do Estado como agente da produção do espaço, a discussão aqui realizada não se propõe a definir os agentes informais, sem, contudo, perder de vista seu papel fundamental na estruturação metropolitana.

Desse modo, no que se refere aos agentes formais de produção do espaço, o seguinte panorama geral metropolitano pode ser inicialmente traçado: 


\section{Quadro 1 - Identificação inicial dos agentes formais de produção do espaço e sua atuação}

\begin{tabular}{|c|c|c|}
\hline Categoria Geral & Agente & \\
\hline Poder Público & Estado & $\begin{array}{l}\text { Provisão de infraestrutura geral; } \\
\text { Regulamentação do uso e ocupação do solo; } \\
\text { Controle fiscal sobre atividades; } \\
\text { Produção imobiliária para determinados grupos sociais. }\end{array}$ \\
\hline Serviço Público & $\begin{array}{l}\text { Serviço de Registro } \\
\text { Imobiliário (cartórios) }\end{array}$ & $\begin{array}{l}\text { Registro de parcelamentos do solo; } \\
\text { Registro de empreendimentos imobiliários; } \\
\text { Registro de transações imobiliárias; } \\
\text { Controle da propriedade formal da terra e imobiliária; } \\
\text { Recolhimento das respectivas taxas e impostos tabelados. }\end{array}$ \\
\hline Proprietários & Proprietário fundiário & Busca pela captação da máxima renda da terra. \\
\hline Proprietários & $\begin{array}{l}\text { Proprietário imobiliário } \\
\text { (não usuário) }\end{array}$ & Busca pela obtenção do máximo lucro sobre o imóvel. \\
\hline Capitalistas & Urbanizadoras & $\begin{array}{l}\text { Execução de parcelamentos do solo, especialmente loteamentos; } \\
\text { Produção de infraestrutura pontual; } \\
\text { Busca a obtenção do máximo lucro sobre o empreendimento. }\end{array}$ \\
\hline $\begin{array}{l}\text { Capitalistas } \\
\text { empreendedores }\end{array}$ & Incorporadoras & $\begin{array}{l}\text { Captação financeira; } \\
\text { Permuta de terrenos; } \\
\text { Lançamento e execução do empreendimento; } \\
\text { Venda das unidades produzidas pré-conclusão; } \\
\text { Busca a obtenção do máximo lucro sobre o empreendimento. }\end{array}$ \\
\hline $\begin{array}{l}\text { Capitalistas } \\
\text { empreendedores }\end{array}$ & Construtoras & $\begin{array}{l}\text { Captação financeira; } \\
\text { Permuta de terrenos; } \\
\text { Lançamento e execução do empreendimento; } \\
\text { Venda das unidades produzidas pós-conclusão; } \\
\text { Busca a obtenção do máximo lucro sobre o empreendimento. }\end{array}$ \\
\hline Intermediários & Arquitetos e urbanistas & $\begin{array}{l}\text { Elaboração dos projetos; } \\
\text { Criação de imagens para uso publicitário; } \\
\text { Acompanhamento das obras de execução. }\end{array}$ \\
\hline Intermediários & Publicitários & Produção de anúncios e marketing para auxílio de vendas. \\
\hline Intermediários & Imobiliárias/ Corretores & $\begin{array}{l}\text { Avaliação imobiliária; } \\
\text { Negociações e vendas. }\end{array}$ \\
\hline $\begin{array}{l}\text { Instituições } \\
\text { financeiras }\end{array}$ & $\begin{array}{l}\text { Bancos e agências de } \\
\text { crédito }\end{array}$ & $\begin{array}{l}\text { Disponibilização de crédito para o parcelamento e construção; } \\
\text { Disponibilização de crédito para a aquisição fundiária e imobiliária. }\end{array}$ \\
\hline Usuários & Proprietários & $\begin{array}{l}\text { Extração do valor de uso de uma determinada propriedade; } \\
\text { Busca pela obtenção do máximo lucro sobre o imóvel, espera por } \\
\text { uma valorização do bem. }\end{array}$ \\
\hline Usuários & Locatários & Extração do máximo valor de uso de uma determinada propriedade. \\
\hline $\begin{array}{l}\text { Movimentos } \\
\text { populares }\end{array}$ & Ativistas e apoiadores & $\begin{array}{l}\text { Luta por direitos e visibilidade de questões sociais, manifestada } \\
\text { por meio de atos organizados, (reuniões, assembleias, petições, } \\
\text { manifestações, paralizações, etc.); } \\
\text { Questionamento de posturas hegemônicas e determinadas decisões } \\
\text { políticas. }\end{array}$ \\
\hline
\end{tabular}

Fonte: elaborado pela autora, em 2019. 
Tal panorama de atuação dos agentes se relaciona a diferentes escalas de interação e poder de interferência na produção e valorização do espaço, por exemplo, se comparada a influência da atuação do Estado ou dos empreendedores com o exercício dos agentes intermediários. No entanto, é a correlação entre todos os agentes que configura os processos de valorização da terra e, concomitantemente, de metropolização. Logo, compreender seus papeis individualmente significa adentrar nos componentes fundamentais da estruturação urbana.

Com relação ao poder público, diferentes níveis de intervenção são possíveis nesses processos: desde a atuação direta por meio de desapropriações, cessões, compras e vendas, até formas indiretas, como nos casos de provisão de infraestrutura e serviços, tributação, regulação do uso do solo e mecanismos de financiamento (Plambel, 1987). Jaramillo (2009) comenta que reconhecer o papel do Estado como agente decisivo é fundamental para a compreensão plena do funcionamento do mercado de terras e imobiliário, base para a estruturação urbana. Segundo o autor, a atuação do Estado pode ser dividida em quatro linhas com reflexos diversos: a via fiscal, de cobrança de impostos; a regulamentação do uso do solo urbano; a provisão de infraestrutura; e a prática imobiliária, no papel de proprietário de terras ou produtor do espaço construído.

No contexto da RMBH, área de interesse deste trabalho, cabe pontuar a estrutura atual do poder público no âmbito da atuação metropolitana, uma vez que apresenta especificidades institucionais. Conforme comenta Tonucci Filho (2012), o arranjo institucional da RMBH é conformado a partir de $2004^{6}$ por três instâncias e dois instrumentos: Assembleia
Metropolitana, Conselho Deliberativo de Desenvolvimento Metropolitano e Agência de Desenvolvimento Metropolitano; e, como instrumentos, o Fundo de Financiamento Metropolitano e o Plano Diretor de Desenvolvimento Integrado da Região Metropolitana (PDDI-RMBH). Enquanto a Assembleia é a responsável pela proposição de macrodiretrizes de atuação, o Conselho trata dos assuntos relacionados ao PDDI, ao Fundo de Desenvolvimento Metropolitano e às Funções Públicas de Interesse Comum. Já a Agência é uma autarquia que tem funções executivas, cuida da articulação para implementação do PDDI e dá suporte aos municípios integrantes da $\mathrm{RMBH}^{7}{ }^{7}$ Assim, importa ressaltar o papel fundamental que tal estrutura exerce tanto no fomento da articulação entre as diferentes estâncias de representatividade quanto na proposição de diretrizes metropolitanas unificadas, o que constitui um passo de extrema relevância para a efetividade do planejamento e desenvolvimento em escala regional.

\section{Do arraial à metrópole regional: panorama da formação da RMBH}

Belo Horizonte, cidade planejada no final do século XIX para abrigar a capital política e administrativa do estado de Minas Gerais, vive desde sua gênese um contínuo processo de expansão urbana associado, em grande parte, à industrialização e, fundamentalmente, à segregação socioespacial. Diretamente atrelada à valorização do espaço, a segregação foi inicialmente determinada no plano inaugural da cidade e posteriormente reproduzida pelo 
mercado imobiliário e de terras. Inaugurada em 1897, Belo Horizonte foi fundada a partir do ímpeto modernizador estimulado pelo início da República Brasileira. A tentativa de adequação nacional às novas bases disseminadas configurou-se na cidade tanto politicamente, por meio da alteração da capital do estado de Minas Gerais, quanto espacialmente, como materialização do pensamento higienista-positivista e de um modo de vida considerado moderno e vanguardista (Lemos, 2010).

Assim, o plano inaugural idealizado pela Comissão Construtora da Nova Capital (CCNC), apresentado em 1895, previa a setorização da cidade em áreas com uso e ocupação determinados (zonas urbana, suburbana e de sítios) e privilegiava a definição do traçado e provisão de infraestrutura e serviços na porção mais central, a zona urbana, em uma clara tentativa de expansão centrífuga (Guimarães, 1991). A subestimação do grande contingente operário e trabalhador de baixa renda na capital associada à estratégia de zoneamento espacial tiveram como consequência inicial a instalação também na zona urbana de parte dessa população, o que originou as primeiras vilas e favelas belo-horizontinas. Contudo, as contínuas políticas de ordenamento, o restrito aparato regulatório, a pequena disponibilidade de terras pelo Poder Público e seus altos valores inviabilizaram a permanência dessa população na área central. Desse modo, já nas primeiras décadas do século $X X$, novos bairros suburbanos são continuamente adensados e reconfiguram a lógica de expansão a partir do centro prevista para a cidade (Plambel, 1986).

Concebida para abrigar inicialmente até 30.000 habitantes, com crescimento futuro para 200.000 habitantes, a população estimada na inauguração de Belo Horizonte era de
12.000 habitantes, e, em 1912, o registro já indicava 38.822 moradores. Os dados habitacionais apresentavam a seguinte configuração em 1912: 12.033 moradores na zona urbana, 14.842 na zona suburbana e 11.947 na zona de sítios; o que caracterizava mais de $60 \%$ da população belo-horizontina instalada além dos limites urbanos nas primeiras décadas do século XX (Perpétuo e Corrêa, s/d). Tal conjuntura de explosão demográfica e subversão do ordenamento territorial levou à emergência de se repensar o plano inaugural, o que gerou, nas décadas seguintes, diversas proposições de reordenamento e de obras reestruturantes.

A gestão de Juscelino Kubitschek (19021976) na prefeitura de Belo Horizonte (19401945) inaugurou um novo período no que se refere ao planejamento urbano e às obras públicas e de infraestrutura na cidade. Associadas ao contexto político-econômico nacional iniciado após a Revolução de 1930, de priorização das bases industriais em substituição ao modelo agrário-exportador, foram incorporadas por Kubitschek diretrizes elaboradas por Lincoln de Campos Continentino (1900-1976) no Plano de Urbanização de Belo Horizonte (1941), ${ }^{8}$ como a criação das Cidades Industrial e Universitária e o lançamento de novos bairros, como a Pampulha e a Cidade Jardim; além de investimentos massivos no sistema viário. Tais medidas possibilitaram a continuidade e a aceleração do processo de expansão da cidade, que foi marcado nesse momento pela generalização da dispersão de loteamentos para além da região central, ocasionada, sobretudo, pelos altos valores das terras oriundos do estímulo à verticalização (ibid.).

Dentro da conjuntura de crescente industrialização nacional e estadual, a criação de uma Cidade Industrial nas proximidades 
da capital mineira relacionava-se, sobretudo, à necessidade de suporte à indústria pesada não comportada pela zona industrial de Belo Horizonte. ${ }^{9}$ Instituída pelos decretos-lei estaduais n. 770 e 778 de $1941,{ }^{10}$ a cidade industrial Juventino Dias, localizada no município de Contagem, só se consolida, de fato, na década de 1950, com a melhoria da disponibilidade de infraestrutura por parte do Estado, o que inclui a criação da Cemig (Companhia de Energia de Minas Gerais) em 1952, o asfaltamento das rodovias de ligação a São Paulo e Rio de Janeiro, além da criação do Anel Rodoviário (Tonucci Filho, 2012). A atuação do Poder Público nesse contexto reflete tanto social quanto espacialmente na dinâmica metropolitana do período. Observa-se o aumento significativo na década de 1950 do número de migrações para as proximidades da Cidade Industrial, bem como o aumento do número de parcelamentos do solo no entorno e nos municípios próximos, tais como Betim e Ibirité. Nesse cenário, enquanto o centro principal de Belo Horizonte perde gradativamente seu papel concentrador de comércio terciário, deslocado para o vetor sul, o vetor oeste consolida-se como polo industrial, o que intensifica seu processo de expansão no período. 0 entorno da Cidade Industrial configura-se como primeira frente de conurbação da Região Metropolitana, eixo de ocupação contínua formada por partes dos municípios de Belo Horizonte, Contagem e Ibirité (Plambel, 1986).

No final da década de 1960 e início de 1970, período mais autoritário do governo militar brasileiro, inicia-se um novo momento de crescimento da economia nacional. A ampliação do aparato regulatório estatal e a disponibilidade de recursos naturais fizeram com que Belo Horizonte recebesse novos investimentos, o que alavancou economicamente os principais centros industriais existentes na aglomeração metropolitana: a cidade industrial Juventino Dias, o parque siderúrgico de Betim e a cidade industrial do município de Santa Luzia (Tonucci Filho, 2012). Destaca-se o papel da instalação da refinaria Gabriel Passos (Regap 1967) e da Fabbrica Italiana Automobili Torino (Fiat -1973, inaugurada em 1976), ambas em Betim, na consolidação do eixo oeste como principal vetor metropolitano de industrialização, bem como na propulsão da RMBH como produtora de bens intermediários e de consumo durável naquele período.

Ainda nesse contexto autoritário e centralizador, foi promulgada a lei complementar n. 14/1973, que institucionaliza as regiões metropolitanas brasileiras. Nela figurava a intenção de se promover um planejamento integrado, por meio da intervenção do Estado no desenvolvimento econômico e social, bem como amortização das questões urbanísticas, de recursos naturais, infraestrutura e saneamento instauradas nos principais centros urbanos nacionais. Em Minas Gerais, o processo de planejamento da região metropolitana já havia sido iniciado em 1971, com a criação do Plambel, órgão de planejamento que, em 1974, foi convertido em uma autarquia estadual. O Plambel tinha sua atuação condicionada pelas prioridades federais, uma vez que atuava como intermediário responsável pelo repasse de recursos e, por essa razão, voltou-se, em seu período inicial, fundamentalmente, para o planejamento e a execução de obras de saneamento e transportes. Desse modo, os gastos públicos favoreciam principalmente a iniciativa privada, que se apropriava da valorização das terras contempladas com infraestrutura e elevava a oferta de parcelamentos para rendas 
mais altas, em detrimento da disponibilidade de moradias populares. Tais medidas, voltadas para o consumo do espaço pelas elites, eram parte do processo de consolidação da expansão metropolitana formal de Belo Horizonte, o que resultou no agravamento das desigualdades espaciais e sua reprodução contínua nos anos seguintes (Plambel, 1986).

As décadas de 1980 e 1990 são marcadas pela crise e recessão econômica, associadas, no período, às raízes da reestruturação produtiva e ao processo de decadência do modo de produção fordista e do "Estado de bem estar social". O resultado de tal conjuntura foi o aumento do desemprego e do subemprego, o agravamento das condições de moradia e o crescimento da informalidade, o que fortaleceu movimentos sociais e urbanos em busca de "melhores condições e acesso aos serviços urbanos básicos nas grandes cidades" (Tonucci Filho, 2012, p. 91). O enfraquecimento da indústria contrapôs-se, no período, à ampliação da atividade minerária e do setor terciário, este último associado em grande parte à informalidade. No que se refere às obras de transporte no período, foram ampliadas as linhas de ônibus e implantado o trem metropolitano de ligação leste-oeste e, para articular os dois eixos, foi implantado o complexo viário e de transportes da Lagoinha (Plambel, 1986).

Regionalmente, a polaridade entre a área central de Belo Horizonte e a centralidade do vetor industrial, Contagem-Betim, permanecia evidente, a despeito da crescente atração da população para o eixo sul e dos investimentos em grandes equipamentos no eixo norte (shopping center, hipermercados, etc.). Tais investimentos associados à conjuntura macroeconômica impulsionaram as concentrações populacionais existentes na região oeste, o que, devido à dificuldade de absorção populacional de novas áreas de expansão, teve como consequência a ampliação daquelas já instauradas (Tonucci Filho, 2012). No mesmo período, são reforçados os processos de controle da expansão urbana: flexibilixação das exigências a novos parcelamentos dentro da RMBH e recomendação de restrição nos municípios limítrofes, com o intuito de evitar a implantação massiva de empreendimentos para além da região metropolitana; definição de perímetros de expansão; elaboração de diretrizes de localização de habitação social; além da formulação de leis de uso e ocupação do solo para os demais municípios metropolitanos, a exemplo de Belo Horizonte. Essas medidas resultaram, dentre outras consequências, na institucionalização do colar metropolitano, expandindo o perímetro sob gerência do Plambel (Plambel, 1986). Costa (2012, p. 83) comenta sobre o processo de estruturação metropolitana de Belo Horizonte e sua conformação centro-periferia:

Ao longo de seu primeiro século de existência, Belo Horizonte foi se transformando de um idealizado projeto de cidade/capital em cidade industrial, desta em metrópole periférica, para no momento atual expandir sua área de influência na forma de uma urbanização dispersa, extensiva, em direção a um largo entorno regional que transcende os limites formais da região metropolitana e seu colar. [...] Assim como o espaço urbano-metropolitano revela o acúmulo desses tempos e formas da urbanização, tanto centro quanto periferia se transformam e se interpenetram, ainda que conservem na essência seus atributos definidores. (Ibid., p. 83) 
$O$ final do século $X X$, associado às consequências do processo de reestruturação produtiva, representa globalmente a passagem do modo produtivo e de desenvolvimento fordista para o chamado sistema de acumulação flexível. O fordismo estruturou-se nos países centrais sob profunda divisão do trabalho industrial, produção em massa, modo de vida atrelado ao consumo e alta regulamentação estatal enquanto mediador da relação capital e trabalho (Ferreira,1997). Já o sistema de acumulação flexível, impulsionado pelo processo de reestruturação produtiva das últimas décadas do século $X X$, resultou na desintegração especializada do trabalho, também associada à terceirização das atividades; na expansão espacial do processo de produção, diretamente relacionada à dependência do setor de serviços; na flexibilização dos produtos e padrões de consumo; assim como na chamada "compressão do espaço tempo" (Harvey, 2007), alteração da lógica de acordos e tomadas de decisão devido à facilidade de comunicação e transportes então em voga. Cabe ressaltar o papel de atração representado pelos países periféricos nesse contexto, recebendo indústrias estruturadas nos países centrais, em busca de mão de obra e insumos mais baratos.

$\mathrm{Na} \mathrm{RMBH}$, a materialização desse processo pode ser principalmente observada na alteração dos padrões de produção da Fiat, localizada no município de Betim. Cardoso (2005) aponta uma reorganização da produção e gestão dos projetos dessa indústria por meio, principalmente, da aplicação de princípios da engenharia simultânea ${ }^{11}$ e da flexibilidade dos trabalhadores envolvidos no processo produtivo, apoiados em tecnologias cada vez mais avançadas. A rigidez apontada por Harvey (2007) como característica fundamental do modo de produção fordista é substituída, no pós-fordismo, por mecanismos híbridos de produção com o intuito de configurar um modelo mais horizontal. Dentre as principais mudanças, ressaltam-se o rearranjo espacial em uma planta fabril mais enxuta e a adoção de sistemas de gestão próprios ao contexto, dentre os quais se destaca o modelo just in time (Cardoso, 2005). Como reflexo da reestruturação produtiva da Fiat, localidades próximas à fábrica foram, nas últimas décadas, intensamente ocupadas por indústrias de componentes automobilísticos e de logística.

Dentro desse contexto, alterações nas características dos municípios do vetor industrial da RMBH são observadas, como o considerável crescimento populacional e a quantidade expressiva de áreas parceladas nas últimas décadas, ainda que parte delas permaneça desocupada. Conforme os dados demográficos do IBGE, os municípios de Igarapé, Juatuba, São Joaquim de Bicas e Sarzedo figuram entre os cinco maiores crescimentos populacionais da RMBH no período 2000-2010, acompanhadas de Lagos Santa, no eixo norte de expansão. Ademais, cabe ressaltar que todos os municípios do vetor oeste apresentaram crescimento superior à taxa regional.

Os anos 2000 foram tomados por um novo período de crescimento econômico em nível nacional, acompanhado da internacionalização de capitais. Tonucci Filho (2012) faz um panorama do contexto da RMBH na primeira década do século XXI e comenta que, em contraposição ao período anterior de redução dos investimentos públicos, nos anos 2000 é retomada, em Belo Horizonte, uma série de intervenções que dinamizam o mercado imobiliário e a construção civil, acelerando processos de verticalização e renovação de áreas 
consolidadas, acompanhados da valorização das terras e imóveis, além da expansão do mercado informal nas áreas periféricas. Dentre essas intervenções, destacam-se, além do vetor norte da região - criação da Linha Verde, implantação da Cidade Administrativa do governo do estado de Minas Gerais, duplicação da avenida Cristiano Machado -, as obras viárias e sanitárias no vale do Ribeirão Arrudas, nas cidades de Belo Horizonte e Contagem, e os investimentos rodoviários que perpassam parte do vetor oeste de expansão, na MG-050, BR-262 e BR-491. Tais obras viárias têm especial relevância no contexto estudado, uma vez que facilitaram a ligação de municípios do vetor oeste ao polo regional, bem como a outras centralidades estaduais. Soraggi (2012) comenta sobre a potencialização da atratividade nos municípios de Juatuba e Mateus Leme nesse contexto da primeira década dos anos 2000 , tanto para usos industriais, quanto para a provisão de habitações populares a partir de programas sociais, especialmente o Programa Minha Casa Minha Vida (PMCMV).

Desde 2002, a RMBH apresenta a estrutura que perdura até a atualidade: formada por 34 municípios mais o colar metropolitano que, reestruturado em 2016, hoje é composto por 16 municípios. No que se refere às práticas estatais de tentativa de ordenamento do território, a primeira década do século XXI foi de extrema relevância para a $\mathrm{RMBH}$, com o início das discussões sobre o Plano Diretor de Desenvolvimento Integrado (PDDI). Elaborado conjuntamente por técnicos, professores e alunos sob coordenação do Centro de Desenvolvimento e Planejamento Regional da Universidade Federal de Minas Gerais (Cedeplar UFMG), o PDDI apresentou-se também como tentativa de promoção de um planejamento regional participativo. Tonucci Filho (2012) comenta a importância nesse período dos trâmites políticos iniciados pelo governo do estado de Minas Gerais como tentativa de formalizar o aparato jurídico-institucional necessário à regulação da gestão metropolitana do território. Em 2004, a emenda à Constituição Estadual n. 65 alterou a Carta Constitucional de 1989 e estabeleceu novas instâncias de planejamento das regiões metropolitanas mineiras, como foi elucidado em seção anterior.

Cabe ressaltar que, além das macrodiretrizes e das orientações metodológicas para a elaboração do PDDI, determinadas em seu termo de contratação, os seguintes aspectos foram tomados como pressupostos:

[...] Construção do sentido de cidadania metropolitana; construção da solidariedade metropolitana; ampliação da inclusão social e econômica; fortalecimento da justiça social e ambiental; reconhecimento/redução das desigualdades e pobreza; reconhecimento/valorização das diversidades socioambientais; novo papel nacional e regional da RMBH; "Novo Pacto" metropolitano; e inversão das prioridades metropolitanas. (Ibid., p. 173)

Tonucci Filho (ibid.) comenta, ainda, que conjugado a tais pressupostos, o plano teve como princípio e um dos objetivos centrais a criação de um processo permanente de planejamento metropolitano, incluindo a universidade e os demais agentes na tentativa de propagação de conhecimento sobre a RMBH. ${ }^{12}$ A ideia de reestruturação do território regional mediante a criação de uma metrópole compacta, integrada e policêntrica permeia o plano, o que resultou na indicação de outros centros, de diferentes escalas, articulados ao 
polo metropolitano por eixos viários propostos. Centros estes originados de um estudo detalhado de dimensões diversas do contexto metropolitano (UFMG, 2011). Aponta-se, contudo, que, apesar do esforço de coordenação iniciado pelo plano metropolitano, o controle efetivo das repercussões da valorização da terra exige a articulação com as esferas locais do planejamento, o que também foi potencializado pela revisão dos planos diretores de municípios da $\mathrm{RMBH}$ realizados por equipe semelhante à de elaboração do PDDI e macrozoneamento em 2018.

Costa (2012) faz um panorama das transformações espaciais recentes na RMBH extraídas dos estudos para a elaboração do PDDI, dentre as quais se destacam: 0 adensamento e valorização imobiliária das áreas centrais, sobretudo de Belo Horizonte; o adensamento construtivo e demográfico das "áreas periféricas centrais", especialmente as Zonas Especiais de Interesse Social (Zeis), mas também as periferias populares fundadas pela autoconstrução; a crescente dispersão urbana e reprodução da fragmentação espacial já existente nas áreas centrais, mais equipadas e valorizadas; a alta taxa de vacância fundiária e imobiliária; e, por fim, a intensa disputa espacial na expansão metropolitana, pressionando constantemente os usos tradicionais. Esse panorama geral reflete a quantidade de conflitos socioespaciais em constante disputa na metrópole belo-horizontina. Segundo a autora "existem, portanto, diferentes projetos de metrópole em permanente disputa pelo espaço e por legitimidade social e política, envolvendo agentes sociais e interesses distintos, nem sempre identificados como tal e muitas vezes pouco visibilizados" (ibid., p. 88). Pensar sobre a articulação desses agentes e sua interferência no espaço metropolitano leva à questão fundamental deste artigo: qual o reflexo da atuação do poder público na expansão metropolitana da RMBH, especialmente no vetor oeste?

\section{Políticas públicas e o processo de consolidação do vetor industrial de Belo Horizonte}

O histórico de conformação do vetor oeste evidencia o papel fundamental do poder público como articulador do processo de metropolização de Belo Horizonte, além de agente de mediação entre as demandas sociais e os interesses do mercado. Apontado como primeiro eixo de conurbação da RMBH, o vetor oeste tem seu histórico de consolidação diretamente relacionado à produção industrial e à habitação operária. A origem do processo de expansão nessa direção pode ser interpretada como fruto da relação entre infraestrutura viária, valor da terra e atratividade econômica. Foi criada uma conexão com a região central de Belo Horizonte, que, catalisada pela oferta de trabalho proveniente da indústria, configurou um panorama favorável para o parcelamento do solo, facilitado pelo baixo valor das terras na região ainda considerada periférica. Pode-se, assim, observar o papel fundamental do Estado como agente nesse contexto: a implantação da cidade industrial Juventino Dias inicia um processo de provisão de infraestrutura pública que reflete na valorização do solo em suas proximidades. Essas terras passam, então, a ser intensivamente parceladas, mas parcialmente comercializadas, no intuito de obter ganhos ainda maiores (Plambel, 1987). 
Esses ganhos podem ser analisados como reflexo da atividade industrial, conforme discute Jaramillo (2009) sobre a formação das rendas habitacionais e comerciais em decorrência da localização de determinadas indústrias. Plambel (ibid., pp. 136-137) comenta que "apesar do acelerado crescimento demográfico observado na Região, nesta década [1950], o volume de lotes colocados à venda nos municípios de Betim e Contagem ultrapassa, em muito, a demanda gerada exclusivamente para atender a esse crescimento". E completa:

O efetivo funcionamento da Cidade Industrial e a implantação da Mannesmann direcionam para oeste a maioria dos loteamentos realizados nesse período em que a conjuntura nacional se apresenta amplamente favorável ao mercado imobiliário. Esse processo atinge profundamente os municípios de Contagem, Betim e Ibirité e a região do Barreiro. Na década de 1950 são lançados 113 loteamentos em Belo Horizonte, Contagem e Betim, tendo como referência a Cidade Industrial, dos quais 66 localizam-se em Contagem e Betim, representando 5.400 lotes, capazes de abrigar cinco vezes a população desses municípios. Os loteamentos então implantados são ocupados lentamente, devido ao caráter especulativo de seu lançamento. (Ibid., pp. 78-79)

Sobre o valor dos terrenos parcelados nas proximidades da cidade industrial nas primeiras décadas desde sua implantação, cabe acrescentar que:

As análises comparativas dos preços de lançamentos desses terrenos mostram esse caráter especulativo. Como exemplo, o preço de lançamento, em 1952, dos terrenos dos bairros Bandeirantes e Brasil Industrial (entorno do Centro Industrial) foi o mesmo que o do bairro Sion, localizado na zona sul de Belo Horizonte, destinado ao assentamento das populações de média e alta renda e dotado de toda a infraestrutura [...]. (Ibid., pp. 137-138)

Soma-se, à expansão metropolitana inicial à oeste, a consolidação do vetor industrial nos anos seguintes, associada diretamente à possibilidade de ocupação de áreas já parceladas e dotadas de infraestrutura: tanto os bairros operários e os loteamentos populares são intensivamente lançados quanto loteamentos para "sítios de recreio" (ibid.) e lazer. A implantação nas décadas seguintes de outras atividades produtivas de grande porte - Fiat, Regap, Ambev - e a concentração gradual de indústrias de menor escala consolidam o vetor oeste como eixo industrial da RMBH na segunda metade do século XX.

Atualmente, a RMBH vivencia um processo de reprimarização produtiva, especialmente relacionada ao setor minerometalomecânico (Magalhães, Tonucci e Silva, 2011), juntamente com a tentativa de consolidação de sua produção terciária, suportada principalmente pelo projeto de "aeroporto cidade" ou "aerotrópole", como levantou o PDDI (UFMG, 2011). O vetor oeste, nesse contexto, perde protagonismo nos investimentos públicos, principalmente direcionados para o eixo norte, apesar das importantes obras viárias realizadas em seus municípios. Contudo, como comentam Costa e Mendonça (2010), o vetor oeste ainda se apresenta como localização privilegiada de políticas públicas de interferência na expansão metropolitana: 
Em Belo Horizonte identifica-se a decisiva intervenção pública no sentido da produção das chamadas condições necessárias de produção, principalmente industrial, promovendo a valorização de determinados espaços e moldando a expansão urbana subsequente comandada pelo capital imobiliário privado que investiu especialmente no parcelamento do solo. As duas principais direções de expansão metropolitana podem assim ser entendidas: a norte, impulsionada pela criação do complexo turístico-urbanístico da Pampulha e pela localização industrial em municípios como Santa Luzia e Vespasiano; a oeste pela consolidação do eixo industrial ao longo da BR-381, abrangendo Contagem e Betim e em processo de expansão. A década de setenta representou um momento-chave do processo acima mencionado, potencializado pelo crescimento industrial, pela valorização fundiária e pela especialização funcional do espaço oriundo das propostas do planejamento metropolitano. (Ibid., p. 5)

No contexto recente da reestruturação produtiva vivenciado pela $\mathrm{RMBH}$, o PDDI resume as tendências imobiliárias e de parcelamento do solo observadas nos municípios do vetor oeste de crescimento: ${ }^{13}$

[...] os municípios de Contagem e Betim sobressaem pela intensificação da produção de pequenos conjuntos de prédios residenciais, inseridos em áreas já urbanizadas ou de urbanização recente, voltados para as classes de renda média, e também a produção de unidades para populações de menor renda em áreas desocupadas e próximas a Belo Horizonte, incentivada, sobretudo, pelo Programa Federal Minha Casa Minha Vida. Nos demais municípios desse eixo, chama a atenção o grande estoque de lotes sem infraestrutura ou com infraestrutura muito precária (exceção de Itaguara); outra característica observada nesses municípios é a ocorrência de chácaras e sítios de lazer mais voltados para camadas de renda média da própria região. (UFMG, 2011, p. 51)

Ademais, segundo a síntese da dinâmica imobiliária metropolitana do PDDI, o vetor oeste estrutura-se atualmente em uma área de maior valorização nos municípios conurbados ao polo - Contagem, Betim, Ibirité -, especialmente relacionada aos mercados populares e de baixa renda; enquanto os demais municípios, áreas de média valorização, estão associados às expansões dos mercados supracitados, com presença forte de autoconstrução e modalidades informais de ocupação, tanto de novas áreas quanto das áreas já parceladas e vacantes (ibid.). No que se refere ao panorama industrial da área de análise, observa-se presença de concentrações industriais em todos os municípios do vetor, inclusive nos mais distantes do polo, como Mateus Leme e Igarapé, geralmente localizadas nas proximidades dos eixos viários estruturantes, como ao longo da MG-050 e da BR-262.

Cabe comentar, ainda, que sob essa lógica de estruturação a partir da capital, a metrópole belo-horizontina apresenta configuração dispersa e monocêntrica, com diversas frentes de expansão e alto grau de dependência do polo, como observado nos municípios do vetor oeste. A partir de tal panorama traçado pelo PDDI, o plano apresenta uma série de propostas de reestruturação metropolitana, em que 
o ano de 2023 foi determinado como marco temporal de médio prazo e 2050 de longo prazo. Fundamentalmente, tais propostas se apoiam na ideia de transformar a metrópole dispersa e monocêntrica em compacta e policêntrica, o que indica, dentre outros aspectos, um fortalecimento das centralidades de diferentes escalas juntamente com a melhoria da rede de mobilidade (ibid., 2011).

0 vetor oeste nesse cenário, além de englobar um centro metropolitano, localizado em Betim, articula o subcentro de Contagem com o do Barreiro, em Belo Horizonte, e incorpora duas redes de centros microrregionais e locais. Tal estrutura prevê Betim como centralidade regional, com o objetivo de melhorar a coordenação interna do município para garantir um maior aproveitamento social da riqueza gerada; além de facilitar sua articulação direta com as demais cidades integrantes do vetor oeste, com o intuito de diminuir a dependência desses municípios com relação ao polo (ibid.).

Sob tais perspectivas, no que se refere às questões fundiárias, imobiliárias e de uso e ocupação do solo, é possível antecipar um potencial movimento de valorização, especialmente nas proximidades da centralidade metropolitana prevista pelo PDDI, o que implica a necessidade de controle da ocupação do solo dos municípios envolvidos para impedir processos especulativos, vacância e futuras expulsões de populações de baixa renda, como ocorrido no período de implantação da cidade industrial. Observa-se, ainda, a importância de se regular os usos industriais nos municípios do vetor, uma vez que a rede de melhorias viárias implica a atração desses usos para a região, tanto pela proximidade de distritos industriais já existentes (efeitos de aglomeração), quanto pelos baixos valores do solo em muitas áreas, como levantado pelo diagnóstico do PDDI. Cabe lembrar que, segundo Jaramillo (2009), a conjunção entre acesso facilitado e baixos valores fundiários configura localizações especialmente atraentes para a indústria.

Esse panorama regional, apesar de estar em contínua transformação, evidencia reflexos estruturais e simbólicos da ação do Estado no contexto da RMBH. Ele indica que, a despeito do observado crescimento produtivo nos demais vetores de expansão metropolitanos (ibid.), o vetor oeste permanece como eixo industrial de grande relevância na região, com significativos processos de atração de novas indústrias, fomentados tanto pelas medidas integradas de estruturação urbana e de mobilidade regional, quanto por políticas de atração municipal (Soraggi, 2012; Costa e Mendonça, 2010).

\section{Considerações finais}

Este artigo buscou discutir os reflexos da atuação do poder público no processo de metropolização, especialmente com relação às questões fundiárias e de valorização do espaço. Como é notável no breve panorama feito sobre a estruturação urbana da RMBH, a ação forte e centralizadora do Estado perpassou os diferentes momentos do planejamento da cidade. $\mathrm{Na}$ concepção da capital mineira, o poder público por meio da CCNC tenta criar uma lógica de ocupação setorizada, controlada por um forte aparato regulatório que resulta na intensa valorização do solo na área central e na consequente inversão da dinâmica imaginada pelos "planejadores". 
O intenso crescimento demográfico e o agravamento das questões habitacionais, já nas primeiras décadas da cidade, desencadearam diversas tentativas de ordenamento territorial e planejamento de ações do poder público a partir de então. Com o boom demográfico industrial da segunda metade do século XX, a conurbação tornou-se evidente, até que na década de 1970 as primeiras decisões em nível regional começam a ser tomadas com a instituição do Plambel.

Chega-se, então, ao terceiro momento de planejamento da $\mathrm{RMBH}$, marcado pelo esforço realizado na elaboração do PDDI de propor a inversão da dinâmica hegemônica centro-periférica de poder e oportunidades, por meio do incentivo à policentralidade na estruturação regional; além da tentativa de inclusão participativa, que representa um grande avanço em busca de políticas públicas que contemplem os diferentes agentes e grupos socioeconômicos.

Nesse cenário, o vetor oeste tem sua trajetória diretamente atrelada aos processos produtivos industriais, atividade que centraliza grande atenção do Estado, bem como de agentes capitalistas. Sua conformação complexa abarca diferentes atividades e camadas sociais, mas tem função fundamental para reprodução das condições e da força de trabalho, diretamente relacionada à moradia operária. Reflete-se, neste artigo, sobre os processos de valorização e estruturação urbana do vetor, bem como sobre as tendências e prospecções fundiárias e de sua ocupação do solo mais recente.

Do ponto de vista teórico, discute-se, sobretudo, a relação essencialmente contraditória entre os processos de uso do espaço e sua valorização; as características singulares da terra, que exigem ponderações específicas no estudo de seu mercado; bem como a importância de se compreender a atuação dos agentes de produção do espaço para o melhor entendimento da dinâmica de estruturação metropolitana e proposição de políticas públicas socialmente democráticas.

Sob tal conjuntura, este artigo propõe uma visão complexa do espaço metropolitano, que considere não só os fatores econômicos, físicos e locacionais que influenciam na formação dos preços, mas também sua interação com o contexto. Assim, a abordagem realizada intenta indicar uma possível direção teórica do estudo do planejamento e da estruturação metropolitana sob a qual a compreensão dos processos e dos agentes envolvidos tenha tanta relevância quanto sua esperada materialização espacial. Aponta-se, como possível caminho para avançar na discussão proposta neste artigo, a reflexão sobre como a compreensão profunda das variáveis de influência e o transcurso da valorização do espaço metropolitano se apresentam como requisito fundamental para garantir políticas urbanas que contemplem os agentes sociais com menor poder de influência, especialmente no que tange à provisão de habitação e direito pleno à cidade para todos.

\section{[1] https://orcid.org/0000-0002-1680-0155}

Universidade Federal de Minas Gerais, Escola de Arquitetura, Programa de Pós-Graduação em Arquitetura e Urbanismo. Belo Horizonte, MG/Brasil. arq.sofialages@gmail.com 


\section{Notas}

(1) O presente trabalho foi realizado com apoio da Coordenação de Aperfeiçoamento de Pessoal de Nível Superior - Brasil (Capes) - Código de Financiamento 001.

(2) Atualmente a RMBH é constituída por 34 municípios: Baldim, Belo Horizonte, Betim, Brumadinho, Caeté, Capim Branco, Confins, Contagem, Esmeraldas, Florestal, Ibirité, Igarapé, Itaguara, Itatiaiuçú, Jaboticatubas, Nova União, Juatuba, Lagoa Santa, Mario Campos, Mateus Leme, Matozinhos, Nova Lima, Pedro Leopoldo, Raposos, Ribeirão das Neves, Rio Acima, Rio Manso, Sabará, Santa Luzia, São Joaquim de Bicas, São José da Lapa, Sarzedo, Taquaraçú de Minas e Vespasiano. Já o colar metropolitano é composto, hoje, por 16 municípios: Barão de Cocais, Belo Vale, Bonfim, Fortuna de Minas, Funilândia, Inhaúma, Itabirito, Itaúna, Moeda, Pará de Minas, Prudente de Morais, Santa Bárbara, São José da Varginha, Sete Lagoas, Bom Jesus do Amparo e São Gonçalo do Rio Abaixo.

(3) Plambel é o nome dado à autarquia estadual criada em 1974 para o planejamento metropolitano de Belo Horizonte. Extinta em 1996, foi responsável pela elaboração de vasto material técnico de diagnósticos e prospecções relacionadas ao planejamento da RMBH, conforme referências utilizadas neste trabalho. Ver mais sobre a trajetória do Plambel em Tonucci Filho (2012).

(4) O nível de integração municipal foi definido por Diniz e Andrade (2015) conforme pesquisa realizada pelo Observatório das Metrópoles - rede brasileira de pesquisadores e instituições, integrante do Instituto Nacional de Ciência e Tecnologia (INCT) - a partir dos seguintes indicadores: concentração e distribuição de população, produto, rendimentos e fluxos populacionais em movimentos pendulares, realização de funções elementares para as atividades econômicas, além de suporte e infraestrutura aos fluxos entre aglomerações, como a existência de aeroportos, por exemplo. Assim, conforme análise estatística por componentes principais e clusters, os municípios foram classificados nas seguintes categorias: polos, extensão dos polos, muito alto, alto, médio, baixo e muito baixo. Ver mais sobre o método e os resultados em Diniz e Andrade (ibid.).

(5) Ver mais sobre a discussão das teorias econômicas de localização em Parnreiter (2018) e Plambel (1987).

(6) A emenda à Constituição Estadual n. 65, de 25 de novembro de 2004 alterou a redação dos artigos 42 a 50 da Carta Constitucional de 1989 na conformação do novo modelo de gestão metropolitana estadual (Tonucci Filho, 2012).

(7) Ver mais sobre composição e atribuições de cada instância, bem como os gestores e objetivos dos instrumentos, em Tonucci Filho (2012).

(8) Ver mais em: Continentino (1941).

(9) Prevista pela lei estadual n. 98, de 10 de outubro de 1936, a Zona Industrial de Belo Horizonte se situava ao longo da linha férrea, às margens do Ribeirão Arrudas (Plambel, 1979).

(10) Decreto-lei estadual n. 770, de 20 de março de 1941, dispõe sobre a desapropriação dos terrenos para a implantação da Cidade Industrial, e o decreto-lei estadual n. 778, de 19 de junho de 1941, dispõe sobre o aforamento desses terrenos ao Poder Público (Plambel, 1979).

(11) Processo que envolve equipes multidisciplinares responsáveis pelo acompanhamento de toda a cadeia de projeto e produção, apoiadas em recursos tecnológicos (Cardoso, 2005). 
(12) Ver mais sobre o percurso metodológico do PDDI em Tonucci Filho (2012), p. 174.

(13) Cabe informar que o vetor oeste determinado pelo PDDI é expandido com relação àquele proposto neste trabalho: inclui os municípios de Floresta, Rio Manso, Itatiaiuçú e Itaguara (UFMG, 2011).

\section{Referências}

ABRAMO, P. (2007). A cidade com-fusa: a mão inoxidável do mercado e a produção da estrutura urbana nas grandes metrópoles latino-americanas. Revista Brasileira de Estudos Urbanos. Rio de Janeiro, v. 9, n. 2, pp. 25-54.

ALMEIDA, R. P.; MONTE-MÓR, R. L. de M. (2017). Renda da terra e o espaço urbano capitalista contemporâneo. Revista de Economia Política. São Paulo, v. 37, n. 2, pp. 417-436.

CONTINENTINO, L. de C. (1941). Plano de Urbanização de Belo Horizonte (Conferência realizada no 10 Congresso Brasileiro de Urbanismo). Revista Mineira de Engenharia. Belo Horizonte, n. 25/26, pp. 41-59.

CARDOSO, L. A. (2005). A reestruturação pós-fordista da produção e suas consequências sobre as novas formas de gestão de projetos na indústria automobilística brasileira. O caso da Fiasa: Fiat Automóveis S.A. Revista Gestão Industrial. Curitiba, v. 1, n. 2, pp. 70-82.

CORRÊA, R. L. (1989). O espaço urbano. São Paulo, Ática.

COSTA, H. S. de M. (2012). “E nas metrópoles: quem planeja o território? Breve contribuição ao debate a partir da experiência de Belo Horizonte”. In: RIBEIRO, A. C.; LIMONAD, E.; GUSMÃO, P. P. (orgs.) Desafios ao planejamento. Rio de Janeiro, Letra Capital.

COSTA, H. S. de M.; MENDONÇA, J. G. de (2010). "Urbanização recente e disputa pelo espaço na dinâmica imobiliária metropolitana em Belo Horizonte". In: XVII ENCONTRO NACIONAL DE ESTUDOS POPULACIONAIS, ABEP. Anais... Caxambu, pp. 1-17.

DINIZ, A. M. A.; ANDRADE, L. T. de (2015). "Metropolização e hierarquização das relações entre os municípios da RMBH". In: ANDRADE, L. T.; MENDONÇA, J. G.; DINIZ, A. M. A. Belo Horizonte: transformações na ordem urbana. Rio de Janeiro, Letra Capital e Observatório das Metrópoles; Belo Horizonte, PUC-Minas.

FERREIRA, C. G. (1997). O "fordismo", sua crise e algumas considerações sobre o caso brasileiro. Revista Nova Economia. Belo Horizonte, v. 7, n. 2, pp. 165-201.

GUIMARÃES, B. M. (1991). Cafuas, barracos e barracões: Belo Horizonte, cidade planejada. Tese de Doutorado. Rio de Janeiro, Universidade Federal do Rio de Janeiro.

HARVEY, D. (2007). Condição pós-moderna: uma pesquisa sobre as origens da mudança cultural. São Paulo, Loyola.

JARAMILLO, S. (2009). Hacia una teoría de la renta del suelo urbano. Bogotá, Universidad de Los Andes.

LEMOS, C. B. (2010). Antigas e novas centralidades: a experiência da cultura do consumo no centro tradicional de Belo Horizonte. Belo Horizonte, Escola de Arquitetura da UFMG. 
MAGALHÃES, F. N. C.; TONUCCI FILHO, J. B. M.; SILVA, H. (2011). “Valorização imobiliária e produção do espaço: novas frentes na RMBH". In: MENDONÇA, J. G.; COSTA, H. S. M. Estado e capital imobiliário: convergências atuais na produção do espaço urbano brasileiro. Belo Horizonte, C/Arte.

MENDONÇA, J. G. de (2002). Segregação e mobilidade residencial na Região Metropolitana de Belo Horizonte. Tese de Doutorado. Rio de Janeiro, Universidade Federal do Rio de Janeiro.

MORAES, A. C. R..; COSTA, W. M. da (1984). Geografia crítica: a valorização do espaço. São Paulo, Hucitec.

PARNREITER, C. (2018). Geografia Económica: uma introducción contemporânea. Cidade do México, Ed. Universidad Nacional Autónoma de México.

PERPÉTUO, F. A. O.; CORRÊA, L. E. M. (orgs.) (s/d). Memória da economia da cidade de Belo Horizonte. Belo Horizonte, BMG Cultural.

PLAMBEL (1979). O processo de desenvolvimento de Belo Horizonte: 1897-1970. Belo Horizonte.

(1986). A estrutura urbana da RMBH: o processo de formação do espaço urbano 1897-1985. Belo Horizonte.

(1987). O mercado da terra na região metropolitana de Belo Horizonte. Belo Horizonte.

SINGER, P. (1982). "O uso do solo na economia capitalista". In: MARICATO, E. A produção capitalista da casa (e da cidade) no Brasil industrial. São Paulo, Alfa-Ômega.

SORAGGI, A. C. M. (2012). A ampliação do mercado da moradia e a expansão do espaço metropolitano periférico: um estudo sobre a produção de moradia para o 'segmento econômico' em Juatuba/ MG. Dissertação de Mestrado. Belo Horizonte, Universidade Federal de Minas Gerais.

TONUCCI FILHO, J. B. M. (2012). Dois momentos do planejamento metropolitano em Belo Horizonte: um estudo das experiências do Plambel e do PDDI - RMBH. Dissertação de Mestrado. São Paulo, Universidade de São Paulo.

UFMG (2011). Plano de Desenvolvimento Integrado da Região Metropolitana de Belo Horizonte PDDI-RMBH. Produto 4, v. 1 e Produto 6, v. 1. Belo Horizonte, UFMG.

Texto recebido em 16/jun/2019

Texto aprovado em 24/ago/2019 